\title{
Image Processing to Improve Detection of Mesial Temporal Sclerosis in Adults
}

\author{
(D)F. Dahi, (D) M.S. Parsons, (D)H.L.P. Orlowski, (D)A. Salter, (D) S. Dahiya, and (D) A. Sharma
}

\begin{abstract}
SUMMARY: In this retrospective case-control study, we investigated whether an image-processing algorithm designed to exaggerate the intensity of diseased hippocampi on FLAIR images can improve the diagnostic accuracy and interobserver reliability of radiologists in detecting mesial temporal sclerosis-related hippocampal signal alteration. Herein, we share the results of this study that showed that the image processing improved the confidence of radiologists in detecting mesial temporal sclerosis-related signal alteration, allowing an improved sensitivity, specificity, and interobserver reliability.
\end{abstract}

ABBREVIATIONS: MTS = mesial temporal sclerosis; $\mathrm{SI}=$ signal intensity

A confident identification of mesial temporal sclerosis (MTS) based on hippocampal volume loss, signal abnormality, and architectural distortion on MR imaging is important for timely surgical management of refractory epilepsy. ${ }^{1-4}$ Because signal abnormalities may precede volume loss in MTS, improved detection of hippocampal signal abnormalities may help in its early diagnosis and treatment. ${ }^{5}$ Recently, an image-processing algorithm using correlative properties of neighboring pixels has shown promise in selectively enhancing the visual conspicuity of diseased hippocampi. ${ }^{6,7}$ Here we share the results of a retrospective casecontrol study testing whether this image processing could translate into an improved diagnostic performance of radiologists in detecting MTS in adults.

\section{MATERIALS AND METHODS Image Processing and Review}

A blinded coinvestigator processed coronal FLAIR images from 51 subjects with MTS and 51 healthy controls (Table 1) with a proprietary image-processing algorithm (Correlative Image Enhancement) using a custom plug-in for OsiriX Lite (https://www. downloadthat.com/windows/search/osirix_lite_for_windows).

Received October 26, 2018; accepted after revision January 18, 2019.

From the Progressive Physicians Association (F.D), Bethlehem, Pennsylvania; and Mallinckrodt Institute of Radiology (M.S.P., H.L.P.O., A.Sharma), Department of Biostatistics (A.Salter), and Department of Pathology and Immunology (S.D.), Washington University School of Medicine, Washington University in St Louis, St Louis, Missouri.

Please address correspondence to Matthew Parsons, MD, Mallinckrodt Institute of Radiology, Washington University School of Medicine, Campus Box 8131, $510 \mathrm{~S}$

Kingshighway Blvd, St. Louis, MO 63110; e-mail: parsonsms@wustl.edu;

@MattParsonsMD

http://dx.doi.org/10.3174/ajnr.A6022
The algorithm exaggerated the hippocampal signal intensity (SI) if it was considerably higher than that of the normal gray matter as defined by an ROI drawn over the normal-appearing insular cortex. Processed images were saved as a separate DICOM series. Six readers with varied experience levels reviewed baseline and processed images separately, rating the SI of each hippocampus on a 5-point scale: 1 , definitely normal; 2 , probably normal; 3 , possibly normal; 4 , probably abnormal; and 5 , definitely abnormal. They also indicated whether the hippocampal SI was unusually high, suggesting the effect of processing.

\section{Data Analysis}

Differences among the median SI ratings across all readers for baseline and processed images were computed and compared using a paired $t$ test or signed rank test. If one considered the SI ratings of $1-3$ as normal and $4-5$ as abnormal, the effects of processing on the sensitivity, specificity, positive predictive value, negative predictive value, and accuracy of each reader and for all readers were assessed. Sensitivity was additionally assessed for a subgroup of patients in whom the MR imaging findings were originally reported as normal. The effect of processing on the interobserver reliability of identifying hippocampal signal abnormality (SI ratings) was computed using a model-based measure of agreement, which is robust to the underlying disease prevalence. ${ }^{8}$

\section{RESULTS}

All readers reported confluent areas of markedly increased signal (Fig 1) in processed images of 37 (72.5\%) diseased hippocampi. Individual readers reported processing-related foci of markedly 


\begin{tabular}{lll}
\hline & \multicolumn{1}{c}{ Subjects } & Controls \\
\hline Mean age (range) (yr) & $34.6(18-58)$ & $42.8(21-79)$ \\
Men & 24 & 13 \\
Women & 27 & 38 \\
Selection source & Pathology database & RIS search and review \\
Inclusion criteria & Age older than 18 yr & Age older than 18 yr \\
& Pathologically proven MTS & Brain and orbital MRI \\
& & Coronal FLAIR images extending across hippocampi \\
Exclusion criteria & Preoperative coronal FLAIR & Seizures \\
& through hippocampi & Known or imaging suspicion of neurologic disease \\
& not available & known to affect hippocampus \\
Indication for MRI & & Reported hippocampal abnormalities \\
& Refractory epilepsy & Diplopia, cranial neuropathy, visual dysfunction, \\
optic neuropathy, papilledema, retrobulbar pain, \\
MR imaging magnet strength (No.) & & ptosis, ocular findings \\
Coronal 2D FLAIR parameters & $3 T(36) 1.5 T$ (15) & $3 T$ (6) 1.5T (45) \\
Thickness (mm) & & 3 \\
FOV (mm) & 3 & $166 \times 190$ \\
TR (ms) & $180 \times 180$ & $9000-10,000$ \\
TE (ms) & $9000-11,000$ & $80-110$ \\
TI (ms) & $80-110$ & 2500 \\
Matrix & 2500 & $256 \times 224$ \\
\hline
\end{tabular}

Note:-RIS indicates radiology information system.
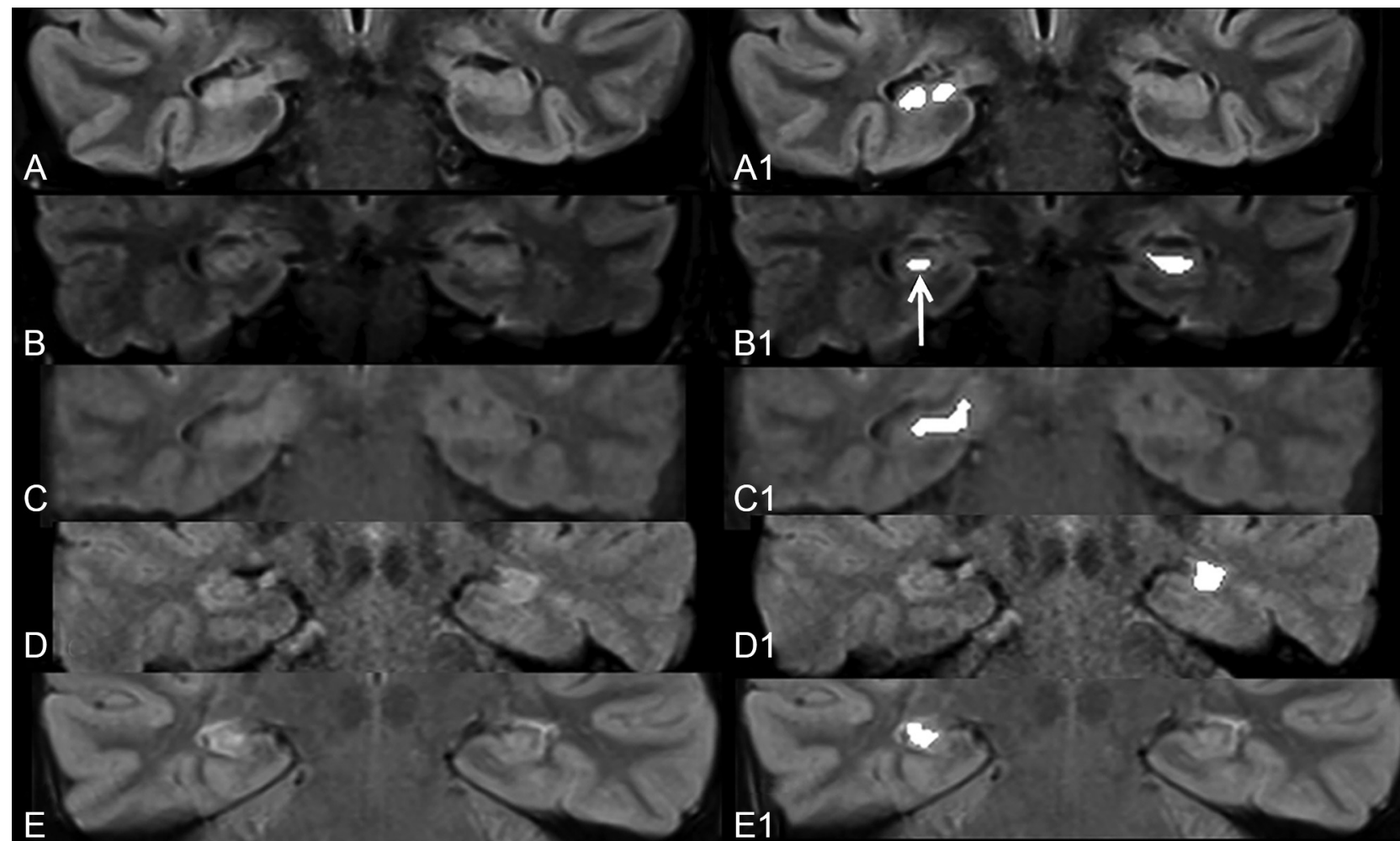

B

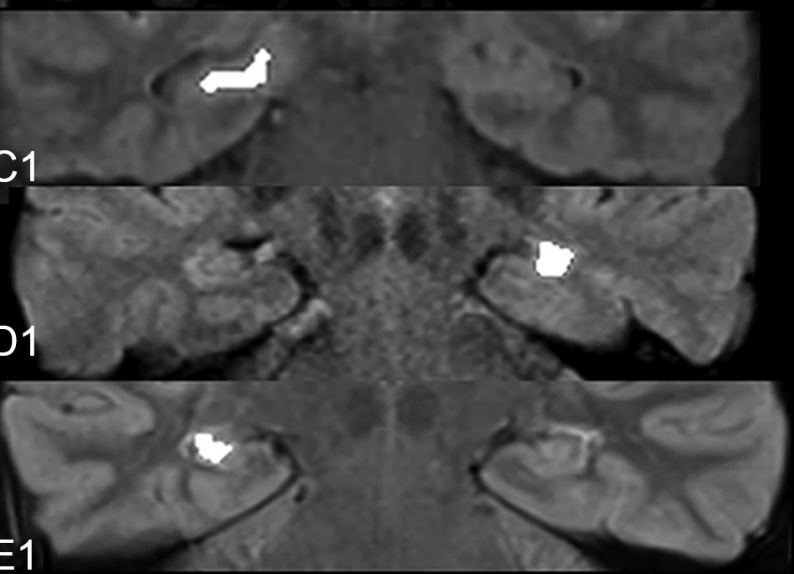

FIG 1. Coronal FLAIR images $(A-E)$ across the medial temporal lobes in patients with pathologically confirmed right-sided $(A, C$, and $E)$ and left-sided $(B$ and $D)$ MTS. Corresponding images following image processing (AT-ET) demonstrate confluent areas of marked exaggeration of signal intensity of the diseased hippocampi. Note a similar exaggeration of signal intensity to a smaller extent in the right hippocampus (arrow) in $B 1$, presumably indicating bilateral disease.

increased SI in 2\%-4.9\% (average, 3.6\%) of control hippocampi (Fig 2).

\section{Effect on Confidence Ratings}

Image processing resulted in an increase in median SI rating for diseased hippocampi $(P<.001$, Table 2$)$ and a decrease in the median SI rating for both left- $(P=.03)$ and right-sided $(P=$ $.003)$ hippocampi in controls.

\section{Effect on Readers' Diagnostic Performance}

An improvement in the average sensitivity, specificity, positive predictive value, negative predictive value, and accuracy was seen

AJNR Am J Neuroradiol 40:798-801 May 2019 www.ajnr.org

799 
after processing (Table 3). The average sensitivity increased by $>10 \%$ (Table 3 ), and readers were able to detect hippocampal signal abnormality in $4 / 10$ (40\%) cases reported as having normal findings on the original clinical reports.

\section{Effect on Interobserver Reliability}

Processing resulted in an improvement in the interobserver agreement in SI ratings for cases of MTS from moderate (Fleiss $\kappa=0.4 ; 95 \%$ CI, $0.2-0.56$ ) to almost perfect (Fleiss $\kappa=0.88 ; 95 \%$ $\mathrm{CI}, 0.80-0.97) .{ }^{9}$ For control hippocampi, interobserver agreement improved from slight to moderate. ${ }^{9}$

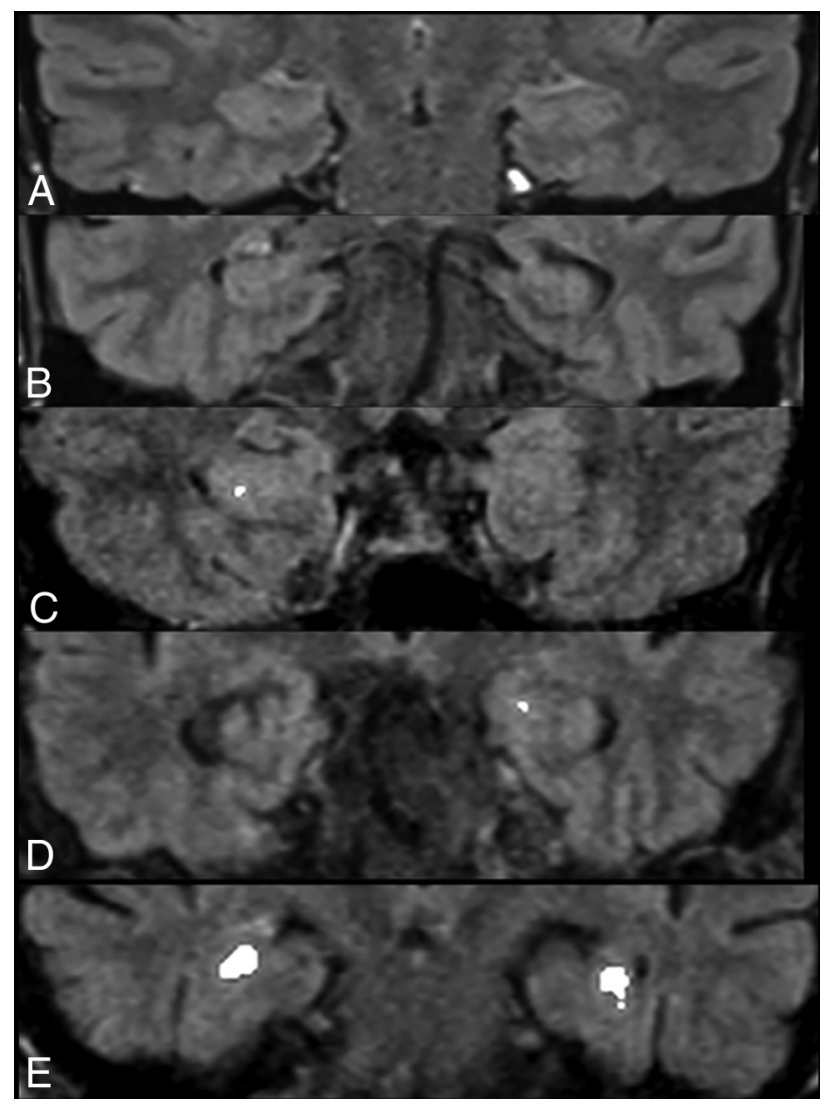

FIG 2. Representative postprocessed coronal FLAIR images across the medial temporal lobes of 5 controls without seizures. Processing did not result in any alteration of hippocampal signal ( $A$ and $B$ ) for most control hippocampi. While punctate $(C$ and $D)$ foci of signal exaggeration were noted in some control hippocampi, false-positive confluent regions of increased intensity mimicking MTS $(E)$ were observed in the bilateral hippocampi of $1(2 \%)$ control.

\section{DISCUSSION}

In our study, an easily recognizable increase in the contrast-tonoise ratio of diseased hippocampi by the image processing ${ }^{6,7}$ translated into substantial improvement in sensitivity when present and slight improvement in specificity when absent. Our results indicate that this processing may help detect MTS in some patients with focal epilepsy with otherwise normal MR imaging findings, ${ }^{10}$ thereby allowing earlier diagnosis and treatment. An improvement in interobserver agreement may make this processing particularly helpful for nonexpert readers, prompting a timely referral to experts.

Unlike volumetry-based techniques, ${ }^{11,12}$ the image processing used in our study relies on highlighting MTS-related signal abnormality. Thus, it is similar to other techniques such as T2 relaxometry and automated FLAIR analysis but may be more generalizable because it does not require comparison with normative data. ${ }^{13-16}$

\section{CONCLUSIONS}

The image-processing algorithm tested by us can improve detection of MTS on MR imaging. In view of a small possibility of false-positive effects of processing, this technique should serve as a complement to a complete epilepsy protocol MR imaging, interpreted in the context of clinical history.

Disclosures: Amber Salter-UNRELATED: Consultancy: Circulation Cardiovascular Imaging. Aseem Sharma—RELATED: Other: Correlative Enhancement LLC, Comments: I hold the intellectual property rights to the image-processing algorithms

\begin{tabular}{|c|c|c|c|c|c|}
\hline Reader & Sensitivity & Specificity & PPV & NPV & Accuracy \\
\hline \multicolumn{6}{|c|}{ Before processing } \\
\hline $\mathrm{R} 1$ & 72.55 & 98.04 & 97.37 & 78.13 & 0.85 \\
\hline $\mathrm{R} 2$ & 60.78 & 98.04 & 96.88 & 71.43 & 0.79 \\
\hline R3 & 43.14 & 100.00 & 100.00 & 63.75 & 0.72 \\
\hline R4 & 58.82 & 92.16 & 88.24 & 69.12 & 0.75 \\
\hline R5 & 86.27 & 80.39 & 81.48 & 85.42 & 0.83 \\
\hline $\mathrm{R} 6$ & 66.67 & 100.00 & 100.00 & 75.00 & 0.83 \\
\hline Mean (SD) & $64.71(14.46)$ & $94.77(7.61)$ & $93.99(7.50)$ & $73.81(7.53)$ & $0.80(0.05)$ \\
\hline \multicolumn{6}{|c|}{ After Processing } \\
\hline $\mathrm{R} 1$ & 74.51 & 96.08 & 95.00 & 79.03 & 0.85 \\
\hline $\mathrm{R} 2$ & 78.43 & 98.04 & 97.56 & 81.97 & 0.88 \\
\hline R3 & 72.55 & 98.04 & 97.37 & 78.13 & 0.85 \\
\hline R4 & 78.43 & 92.16 & 90.91 & 81.03 & 0.85 \\
\hline R5 & 72.55 & 98.04 & 97.37 & 78.13 & 0.85 \\
\hline R6 & 74.51 & 98.04 & 97.44 & 79.37 & 0.86 \\
\hline Mean (SD) & $75.16(2.68)$ & $96.73(2.37)$ & $95.94(2.65)$ & $79.61(1.57)$ & $0.86(0.01)$ \\
\hline
\end{tabular}

Note:-R1 and R2 indicate radiology residents; R3 and R4, neuroradiology fellows; R5 and R6, attending neuroradiologists; PPV, positive predictive value; NPV, negative predictive value.

Table 2: Effect of image processing on signal intensity ratings for subjects with MTS, right-sided control hippocampi, and left-sided control hippocampi on a 5-point scale ${ }^{\mathrm{a}}$

\begin{tabular}{|c|c|c|c|c|c|c|}
\hline & Median & Minimum & $\begin{array}{c}\text { 25th } \\
\text { Percentile }\end{array}$ & $\begin{array}{c}\text { 75th } \\
\text { Percentile }\end{array}$ & Maximum & $P$ \\
\hline Subjects & 4.00 & 1.00 & 1.00 & 2.00 & 4.00 & $<.00$ \\
\hline Subjects (processed) & 5.00 & 1.00 & 1.00 & 2.00 & 5.00 & \\
\hline Controls (R) & 1.00 & 1.00 & 1.00 & 1.50 & 3.50 & $<.01$ \\
\hline Controls (R, processed) & 1.00 & 1.00 & 1.00 & 1.00 & 5.00 & \\
\hline Controls (L) & 1.00 & 1.00 & 1.00 & 1.50 & 2.00 & .03 \\
\hline Controls (L, processed) & 1.00 & 1.00 & 1.00 & 1.00 & 5.00 & \\
\hline
\end{tabular}

Note:- $R$ indicates right; $L$, left.

${ }^{a}$ 1, Definitely normal; 2, probably normal; 3, possibly normal; 4, probably abnormal; 5, definitely abnormal. 
used in this study. I have founded a company (Correlative Enhancement LLC) with the aim of future commercialization of this intellectual property. I am the sole proprietor of the company, and since the inception of the company until now (including the time during which I processed the images for this study), this company has not received funding from any external source. While I used the algorithms to process the images for this study, I did not participate in patient selection, image review, image analysis, or the subsequent statistical analysis; UNRELATED: Consultancy: Biomedical Systems, Comments: As a consultant, I serve as an independent reviewer for imaging studies performed for research by third parties; Patents (Planned, Pending or Issued): I have been issued the patent for the method of image processing used in this and other studies; Stock/Stock Options: GE Healthcare, Comments: I hold approximately $\$ 10,000$ worth of publicly traded GE stocks. Sonika Dahiya —UNRELATED: Employment: Washington University School of Medicine.

\section{REFERENCES}

1. Kuzniecky RI, Bilir E, Gilliam F, et al. Multimodality MRI in mesial temporal sclerosis: relative sensitivity and specificity. Neurology 1997;49:774-78 CrossRef Medline

2. Janszky J, Janszky I, Schulz R, et al. Temporal lobe epilepsy with hippocampal sclerosis: predictors for long-term surgical outcome. Brain 2005;128:395-404 Medline

3. Thom M, Mathern GW, Cross JH, et al. Mesial temporal lobe epilepsy: how do we improve surgical outcome? Ann Neurol 2010; 68:424-34 CrossRef Medline

4. Malmgren K, Thom M. Hippocampal sclerosis-origins and imaging. Epilepsia 2012;53(Suppl 4):19-33 CrossRef Medline

5. Provenzale JM, Barboriak DP, VanLandingham K, et al. Hippocampal MRI signal hyperintensity after febrile status epilepticus is predictive of subsequent mesial temporal sclerosis. AJR Am J Roentgenol 2008;190:976-83 CrossRef Medline

6. Parsons MS, Sharma A, Hildebolt C. Using correlative properties of neighboring pixels to enhance contrast-to-noise ratio of abnormal hippocampus in patients with intractable epilepsy and mesial tem- poral sclerosis. Acad Radiol 2018 Jun 12. [Epub ahead of print] CrossRef Medline

7. Orlowski HL, Smyth MD, Parsons MS, et al. Enhancing contrast to noise ratio of hippocampi affected with mesial temporal sclerosis: a case-control study in children undergoing epilepsy surgeries. Clin Neurol Neurosurg 2018;174:144-48 CrossRef Medline

8. Nelson KP, Edwards D. Measures of agreement between many raters for ordinal classifications. Stat Med 2015;34:3116-32 CrossRef Medline

9. Landis JR, Koch GG. An application of hierarchical kappa-type statistics in the assessment of majority agreement among multiple observers. Biometrics 1977;33:363-74 CrossRef Medline

10. Kwan P, Brodie MJ. Early identification of refractory epilepsy. N Engl J Med 2000;342:314-19 CrossRef Medline

11. Guzmán Perez-Carrillo GJ, Owen C, Schwetye KE, et al. The use of hippocampal volumetric measurements to improve diagnostic accuracy in pediatric patients with mesial temporal sclerosis. $\mathrm{J} \mathrm{Neu}$ rosurg Pediatr 2017;19:720-28 CrossRef Medline

12. Silva G, Martins C, Moreira da Silva N, et al. Automated volumetry of hippocampus is useful to confirm unilateral mesial temporal sclerosis in patients with radiologically positive findings. Neuroradiol J 2017;30:318-23 CrossRef Medline

13. Huppertz HJ, Wagner J, Weber B, et al. Automated quantitative FLAIR analysis in hippocampal sclerosis. Epilepsy Res 2011;97: 146-56 CrossRef Medline

14. Bernasconi A, Bernasconi N, Caramanos Z, et al. T2 relaxometry can lateralize mesial temporal lobe epilepsy in patients with normal MRI. Neuroimage 2000;12:739-46 CrossRef Medline

15. Pell GS, Briellmann RS, Waites AB, et al. Voxel-based relaxometry: a new approach for analysis of $\mathrm{T} 2$ relaxometry changes in epilepsy. Neuroimage 2004;21:707-13 CrossRef Medline

16. Focke NK, Bonelli SB, Yogarajah M, et al. Automated normalized FLAIR imaging in MRI-negative patients with refractory focal epilepsy. Epilepsia 2009;50:1484-90 CrossRef Medline 